\section{S59 \\ PREDICTING ASTHMA IN LATER CHILDHOOD: A GENERAL AND HIGH-RISK POPULATION APPROACH}

${ }^{1} S$ Colicino, ${ }^{1} \mathrm{C}$ Minelli, ${ }^{2} \mathrm{~A}$ Lewin, ${ }^{3} \mathrm{~S}$ Turner, ${ }^{4} \mathrm{~A}$ Simpson, ${ }^{5} \mathrm{SH}$ Arshad, ${ }^{6} \mathrm{AJW}$ Henderson, ${ }^{1} \mathrm{~A}$ Custovic, ${ }^{1} \mathrm{P}$ Cullinan. ${ }^{1}$ Imperial College London, London, UK; ${ }^{2}$ Brunel University London, London, UK; ${ }^{3}$ University of Aberdeen, Aberdeen, UK; ${ }^{4}$ University of Manchester, Manchester, UK; ${ }^{5}$ University of Southampton, Southampton, UK; ${ }^{6}$ University of Bristol, Bristol, UK

\subsection{6/thoraxinl-2017-210983.65}

Introduction Young children commonly wheeze but only some have asthma later in life. Asthma prediction tools have poor predictive performance and few have been validated. We aimed to develop a robust tool for the prediction of asthma at age 10-14 years using readily available information.

Methods we studied 5 UK birth cohorts (the STELAR consortium) and considered two groups: 1. all children recruited at birth and 2. high-risk children on the basis of reported wheezing at $2 / 3$ or 5 years. Two comparable cohorts (Ashford and ALSPAC) were used to select predictors (training sample) and the SEATON, MAAS and Isle of Wight studies to assess predictive performance (validation sample). We included 16187 and 814 children from groups 1 and 2 respectively in the training sample and validated the developed predictive tools in 5320 and 285 children from the validation sample. We considered 40 potential predictors collected at recruitment and at $1,2 / 3$ and 5 years of age: demographic and perinatal information, eczema, hay-fever, respiratory symptoms, environmental and family-related factors. We defined asthma at 1014 years by the presence of both current wheeze and asthma treatment. We compared 5 statistical methods to select variables and estimate coefficients: stepwise regression, classical (LASSO and Elastic-Net, EN), empirical Bayes (EB) and Bayesian (BM) regularisation Methods Predictive performance was assessed using calibration and discrimination measures including area under the ROC curve (AUC).

Results Asthma prevalence at age 10-14 ranged from 7\%$18 \%$ in group 1 and from $32 \%-52 \%$ in group 2 . Frequency of early wheezing, eczema, and paternal asthma were important predictors in all models and both groups. Other selected predictors included birth order, maternal asthma and domestic pets. Specificity and negative predictive value (NPV) were higher in the general population, while sensitivity and positive predictive value (PPV) were higher in high-risk group. BM (AUC 0.77, specificity 0.84 and NPV 0.93) and EN (AUC 0.74 , sensitivity 0.71 and PPV 0.65 ) provided the highest accuracy and discriminative ability predictive ability in the 2 groups, respectively.

Conclusion The use of sophisticated statistical methods in a large, multicentre population demonstrated promising Results in developing an asthma predictive tool.

\section{S60 OMALIZUMAB IN CHILDREN CAN REDUCE ASTHMA EMERGENCY DEPARTMENT PRESENTATIONS: RETROSPECTIVE REAL-WORLD UK DATA}

${ }^{1,2} \mathrm{CS}$ Murray, ${ }^{3} \mathrm{~B}$ Raymond. 'Division of Infection, Immunity and Respiratory medicine, University of Manchester and University Hospital of South Manchester, Manchester Academic Health Sciences Centre, Manchester, UK; ${ }^{2}$ Royal Manchester Children's Hospital, Central Manchester University Hospitals NHS Foundation Trust, Oxford Road, Manchester, UK; ${ }^{3}$ Novartis Pharmaceuticals UK Ltd, Frimley, UK

\subsection{6/thoraxjnl-2017-210983.66}

Introduction and Objectives Omalizumab is indicated as add-on therapy to improve asthma control in children aged $\geq 6$ years with severe persistent allergic asthma. ${ }^{1}$ In the UK, only children with the most severe allergic asthma phenotype are eligible for treatment with omalizumab (as an add-on to optimised standard therapy and who need continuous or frequent $(\geq 4$ courses/year) treatment with oral corticosteroids. ${ }^{2}$ However, published clinical trials tell us little about the likely benefit in this cohort. Real-world studies have been shown to complement Results from clinical trials and have been published with regard to omalizumab in adults. Using real-life data, we aimed to investigate whether emergency department (ED) attendances were reduced in children following the use of omalizumab.

Methods Using Hospital Episode Statistics data from hospitals in England, we examined ED attendance data for children aged 6-16 years who received omalizumab. Children who had received their first dose of omalizumab between 01/01/2011 and 31/12/2013 were included and had asthma related ED activity extracted for the 24 months prior to the date of the first omalizumab injection, and for the subsequent 24 months. Children who had not received a minimum of 24 injections in the subsequent 24 months were excluded from the analysis. Results 192 children (mean age 12.9 years) received their first injection of omalizumab between 01/01/2011 and 31/12/2013, of which 54 children received a minimum of 24 injections and were included in the analysis. There was a significant reduction in the number of children with $\mathrm{ED}$ attendances over the 24 months of omalizumab injections compared with the 24 months prior to starting treatment $(\mathrm{p}=0.001$; figure 1). Also, children had significantly fewer ED attendances during the autumn in the 2 years whilst receiving omalizumab than in the 2 years prior to treatment $(p=0.001)$.

Conclusions Although omalizumab in the UK is generally prescribed to children with more severe allergic asthma than those children who have been included in clinical trials, realworld paediatric data appears to complement clinical trial data, suggesting omalizumab reduces ED attendances in children with severe allergic asthma.

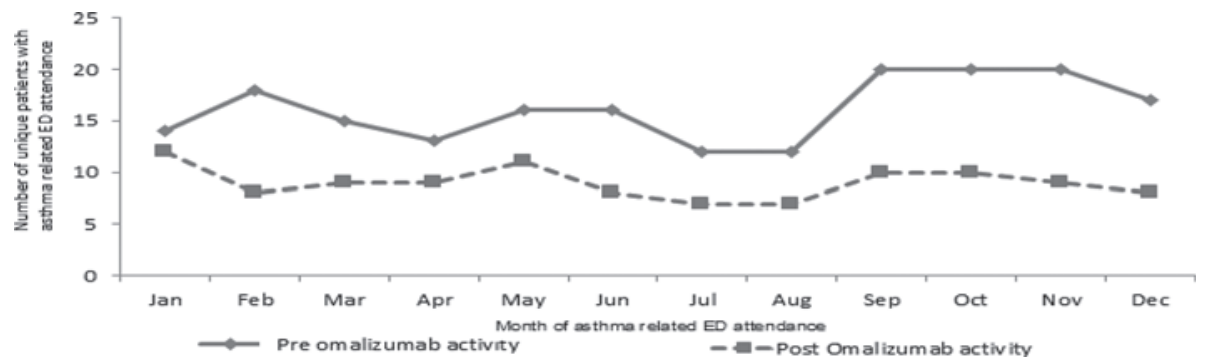

Abstract S60 Figure 1 Number of unique patients with asthma related ED attendance per month during the 24 months pre-omalizumab (ED preactivity) and the first 24 months on omalizumab treatment (ED post-activity) in children aged 6-16 years in England 2011-2013. 


\section{REFERENCES}

1. Omalizumab SmPC. https://www.medicines.org.uk/emc/medicine/24912

2. NICE Guidance 278. https://www.nice.org.uk/guidance/ta278

\section{S61 A SYSTEMATIC REVIEW AND META-ANALYSIS FOR THE ASSOCIATION OF PARACETAMOL AND CHILDHOOD ASTHMA: BREATHING NEW LIFE INTO AN OLD MYTH?}

${ }^{1} \mathrm{JJ}$ Kenth, ${ }^{2} \mathrm{~J}$ Finnerty, ${ }^{1} \mathrm{R}$ Perkins, ${ }^{3} \mathrm{KE}$ Bramley. 'Royal Manchester Children's Hospital, Manchester, UK; ${ }^{2}$ Pennine Acute Trust, Manchester, UK; ${ }^{3}$ Royal Infirmary of Edinburgh, Sutton Coldfield, UK

\subsection{6/thoraxjnl-2017-210983.67}

Introduction and Objectives Paracetamol is globally the most frequently prescribed drug amongst infants being employed in a variety of different contexts - from acute febrile illnesses to postoperative analgesia. Prior epidemiological evidence had long inferred a correlation between paracetamol to the ontogeny and exacerbation of asthmatic symptoms, leading to some clinicians advocating for a total prohibition. In view of the evidence being primarily from cohort studies, uncertainty persisted about the strength of the evidence as concerns were raised about the validity of observational cohort studies to ascertain causation, particularly in the absence of a placebo or a control group.

Methods A systematic review of the medical literature search was performed from bibliographic databases that included: Pubmed/Medline, EMBASE, CINAHL, CENTRAL, and Google Scholar; from 1975 until June 2017, using a prospective and explicit search criteria. The Mantel Haenszel (MH) method using a random effects model calculated the weighted odd ratio (OR).

Results 256 studies were identified from abstracts and titles with 9 studies being included in this review: 7 were prospective cohorts studies and two RCTs. The study ascertained that paracetamol was not associated with increased risk of asthma symptoms: MH-OR 0.083 (95\% CI 0.051-0.1332). However, the substantially high degree of heterogeneity $\left(\mathrm{I}^{2}=99 \%\right)$ illustrated the limitations of combining the weighted $\mathrm{MH}-\mathrm{OR}$ from cohort studies. Four prospective cohort studies reported a statically significant association between paracetamol and asthma symptoms, whereas a well conducted, rigorous, double blinded RCT found no significant difference. The potential mechanisms by which paracetamol induced bronchospasm has not been fully elucidated; however the depletion of glutathione in lung parenchyma, increased intra and extra-mitochondrial oxidative stress, and reactive oxygen species are all thought to have a contributory role.

Conclusions Whilst prior cohort studies had previously inferred causation between paracetamol and the exacerbations of asthma symptoms, a well conducted and rigorous RCT demonstrated no significant association. Notwithstanding the limitations of meta-analysis, we recommend that paracetamol remains safe, with usage being contextualised to follow current best practice paradigms. Reflectively, the review raises the caveat of the unquestioned advocacy of paracetamol or any drug as a cultural axiom.

\section{S62 IDENTIFYING THE CHILD (5-12 YEARS) WITH ASTHMA AT INCREASED RISK OF ATTACKS: THE AT-RISK CHILD WITH ASTHMA (ARC) SYSTEMATIC REVIEW}

\begin{abstract}
${ }^{1} \mathrm{~A}$ Buelo, ${ }^{1} \mathrm{~S}$ Mclean, ${ }^{1} \mathrm{~J}$ Flores-Kim, ${ }^{2} \mathrm{~S}$ Julious, ${ }^{3} \mathrm{M}$ Shields, ${ }^{4} \mathrm{~J}$ Paton, ${ }^{5} \mathrm{~J}$ Henderson, ${ }^{6} \mathrm{~A}$ Bush, ${ }^{1} \mathrm{H}$ Pinnock. 'Asthma UK Centre for Applied Research, Usher Institute for Population Health Sciences, University of Edinburgh, Edinburgh, UK; ${ }^{2}$ Medical Statistics Group, School of Health and Related Research, University of Sheffield, Sheffield, UK; ${ }^{3}$ School of Medicine, Queen's University Belfast, Belfast, UK; ${ }^{4}$ School of Medicine, College of Medical, Veterinary and Life Sciences, University of Glasgow, Glasgow, UK; ${ }^{5}$ School of Social and Community Medicine, University of Bristol, Bristol, UK; ${ }^{6}$ National Heart and Lung Institute, Imperial College London, London, UK
\end{abstract}

\subsection{6/thoraxinl-2017-210983.68}

Introduction and Objectives Asthma is the commonest longterm condition in children with attacks impacting on both

\begin{tabular}{|c|c|c|c|c|c|c|c|c|c|}
\hline \multirow[b]{2}{*}{ Study or Subgroup } & \multicolumn{2}{|c|}{ Paracetamol } & \multicolumn{2}{|c|}{ Non-Paracetamol } & \multirow[b]{2}{*}{ Weight } & \multirow{2}{*}{$\begin{array}{l}\text { Odds Ratio } \\
\mathrm{M}-\mathrm{H}, \text { Random, } 95 \% \mathrm{Cl}\end{array}$} & \multirow{2}{*}{\multicolumn{2}{|c|}{$\begin{array}{l}\text { Odds Ratio } \\
\mathrm{M}-\mathrm{H}, \text { Random, } 95 \% \mathrm{Cl}\end{array}$}} & Risk of Bias \\
\hline & Events & Total & Events & Total & & & & & $A B C D E F G$ \\
\hline \multicolumn{10}{|l|}{ 1.1.1 Asthma } \\
\hline Amberbir 2011 & 9 & 1006 & 997 & 1006 & $8.2 \%$ & $0.0001[0.0000,0.0002]$ & 4 & & \\
\hline Bakkeheim 2011 & 303 & 1016 & 713 & 1016 & $11.8 \%$ & $0.1806[0.1493,0.2184]$ & $*$ & & \\
\hline Kreiner-Møller 2012 & 77 & 411 & 334 & 411 & $11.3 \%$ & $0.0531[0.0374,0.0755]$ & $\leftarrow$ & & \\
\hline Lesko 2002 & 32 & 632 & 37 & 1247 & $10.7 \%$ & $1.7441[1.0758,2.8276]$ & & 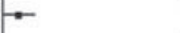 & \\
\hline Lowe 2010 & 148 & 620 & 472 & 620 & $11.6 \%$ & $0.0983[0.0757,0.1277]$ & - & & \\
\hline Rusconi 2011 & 3519 & 16933 & 13414 & 16933 & $12.0 \%$ & $0.0688[0.0653,0.0725]$ & $\cdot$ & & \\
\hline Schnabel 2010 & 2240 & 12733 & 10493 & 12733 & $12.0 \%$ & $0.0456[0.0427,0.0486]$ & $\cdot$ & & \\
\hline Sheehan 2016 & 74 & 150 & 70 & 150 & $10.8 \%$ & $1.1128[0.7073,1.7507]$ & & - & \\
\hline Wickens 2011 & 201 & 914 & 713 & 914 & $11.7 \%$ & $0.0795[0.0637,0.0992]$ & * & & \\
\hline Subtotal $(95 \% \mathrm{Cl})$ & & 34415 & & 35030 & $100.0 \%$ & $0.0827[0.0514,0.1332]$ & & & \\
\hline Total events & 6603 & & 27243 & & & & & & \\
\hline \multirow{2}{*}{\multicolumn{10}{|c|}{$\begin{array}{l}\text { Heterogeneity. } \text { Tau }^{2}=0.49 ; \mathrm{Chi}^{2}=774.58, \mathrm{df}=8(\mathrm{P}<0.00001) ; \mathrm{P}^{2}=99 \% \\
\text { Test for overall effect: } Z=10.25(P<0.00001)\end{array}$}} \\
\hline & & & & & & & & & \\
\hline Total $(95 \% \mathrm{Cl})$ & & 34415 & & 35030 & $100.0 \%$ & $0.0827[0.0514,0.1332]$ & & & \\
\hline Total events & 6603 & & 27243 & & & & & & \\
\hline \multicolumn{7}{|c|}{ Heterogeneity. Tau $^{2}=0.49 ; \mathrm{Chi}^{2}=774.58, \mathrm{df}=8(\mathrm{P}<0.00001) ; \mathrm{I}^{2}=99 \%$} & $0.005 \quad 0.1$ & $10 \quad 200$ & \\
\hline \multicolumn{7}{|c|}{ Test for overall effect: $Z=10.25(P<0.00001)$} & decreases risk & increase risk & \\
\hline \multicolumn{10}{|c|}{ Test for subgroup differences: Not applicable } \\
\hline \multicolumn{10}{|c|}{ Risk of bias legend } \\
\hline \multicolumn{10}{|c|}{ (A) Random sequence generation (selection bias) } \\
\hline \multicolumn{10}{|c|}{ (B) Allocation concealment (selection bias) } \\
\hline \multicolumn{10}{|c|}{ (C) Blinding of participants and personnel (performance bias) } \\
\hline \multirow{2}{*}{\multicolumn{10}{|c|}{$\begin{array}{l}\text { (D) Blinding of outcome assessment (detection bias) } \\
\text { (E) Incomplete outcome data (attrition bias) }\end{array}$}} \\
\hline & & & & & & & & & \\
\hline \multicolumn{10}{|c|}{ (F) Selective reporting (reporting bias) } \\
\hline (G) Other bias & & & & & & & & & \\
\hline
\end{tabular}

Abstract S61 Figure 1 Summary of the included studies, a forest plot for random effects meta-analysis of odd ratios and summary of the risk of bias. 